The University of Southern Mississippi

The Aquila Digital Community

Faculty Publications

$10-31-2019$

\title{
Impact of Hydration Status On Electromyography and Ratings of Perceived Exertion During the Vertical Jump
}

\author{
Paul T. Donahue \\ University of Southern Mississippi, paul.donahue@usm.edu \\ Samuel J. Wilson \\ Georgia Southern University, sjwilson@georgiasouthern.edu \\ Charles C. Williams \\ LaGrange College \\ Melinda Valliant \\ University of Mississippi \\ John C. Garner \\ Troy University
}

Follow this and additional works at: https://aquila.usm.edu/fac_pubs

Part of the Kinesiology Commons

\section{Recommended Citation}

Donahue, P. T., Wilson, S. J., Williams, C. C., Valliant, M., Garner, J. C. (2019). Impact of Hydration Status On Electromyography and Ratings of Perceived Exertion During the Vertical Jump. International Journal of Kinesiology \& Sports Science, 7(4), 1-8.

Available at: https://aquila.usm.edu/fac_pubs/16912

This Article is brought to you for free and open access by The Aquila Digital Community. It has been accepted for inclusion in Faculty Publications by an authorized administrator of The Aquila Digital Community. For more information, please contact Joshua.Cromwell@usm.edu. 


\title{
Impact of Hydration Status on Electromyography and Ratings of Perceived Exertion During the Vertical Jump
}

\author{
Paul T Donahue ${ }^{*}$, Samuel J Wilson ${ }^{2}$, Charles C Williams ${ }^{3}$, Melinda Valliant ${ }^{4}$, John C Garner ${ }^{5}$ \\ ${ }^{1}$ School of Kinesiology and Nutrition, University of Southern Mississippi, 118 College Dr., Hattiesburg, MS 39401 USA \\ ${ }^{2}$ Department of Health Sciences and Kinesiology; Georgia Southern University, Statesboro, GA USA \\ ${ }^{3}$ Department of Exercise Science; LaGrange College, LaGrange, GA USA \\ ${ }^{4}$ Department of Nutrition and Hospitality Management, University of Mississippi, Oxford, MS USA \\ ${ }^{5}$ Department of Kinesiology and Health Promotion, Troy, AL USA
}

Corresponding Author: Paul T Donahue, E-mail: Paul.Donahue@usm.edu

\section{ARTICLE INFO}

Article history

Received: June 01, 2019

Accepted: September 28, 2019

Published: October 31, 2019

Volume: 7 Issue: 4

Conflicts of interest: None

Funding: None

\begin{abstract}
Background: The vertical jumping task is commonly used to assess lower-body power output in athletic populations, in addition to being commonly used to during investigations of hydration and anaerobic performance. Changes in neuromuscular function during a hypohydrated state have been proposed as a potential mechanism to decreases in anaerobic performance. Objectives: The primary purpose of this investigation was to examine the impact of hydration state on electromyography during the vertical jumping task. Methods: Twenty recreationally trained males were tested in three hydration conditions (hypohydrated, euhydrated, and control). Testing included maximal voluntary contractions of the vastus lateralis, vastus medialis, semitendinosus and medial gastrocnemius. Participants performed three maximal countermovement and squat jumps respectively for a total of six jumps in each condition. Both mean muscle activity and percentage of maximal voluntary contraction were calculated across the propulsive phase of each jump. Additionally, measures of RPE and the use of a mood rating scale were used as subjective measures. Results: No differences were seen in mean muscle activity and percentage of MVC in either of the jumping conditions $(p>0.05)$. Significant differences were seen with higher ratings of perceived exertion as well as lower levels of mood ratings after the hypohydrated condition $(\mathrm{p}=0.02$ and $\mathrm{p}=0.048$ respectively). Conclusions: Decrements seen in vertical jump performance during a hypohydrated state appear to be caused from changes other than neuromuscular function and muscle activity. Differences in subjective measures may provide insight into changes in motivational levels and potentially impacting performance.
\end{abstract}

Key words: Electromyography, Dehydration, Recreationally, Athletic Injuries, Musculoskeletal

\section{INTRODUCTION}

Hypohydration has been shown to have a detrimental influence on aerobic based exercise, with altered cardiovascular function and metabolic factors leading to early onset fatigue (Judelson et al., 2007). While still important, maximal anaerobic performance relies less on both cardiovascular and metabolic function than aerobic performance. The vertical jumping task is commonly used as a means to assess lower-body power output and is commonly seen in the hypohydration literature as tool to measure the effect of hydration status on anaerobic performance (Judelson et al., 2007). The more common suggestion that is made to the possible mechanisms of a decrease in anaerobic performance from hypohydration is centered around a change in neuromuscular function if any decrement is seen at all (Fogelholm, 1994; Hoffman, Stavsky, \& Falk, 1995; Vallier et al., 2005;
Viitasalo, Kyröläinen, Bosco, \& Alen, 1987; Walsh, Noakes, Hawley, \& Dennis, 1994). Though this mechanism is commonly suggested as the means to a reduction in performance, results from previous investigations are limited and inconclusive (Bigard et al., 2001; Evetovich et al., 2002; Ftaiti, Grélot, Coudreuse, \& Nicol, 2001; Vallier et al., 2005). Previous investigations that have used electromyography in the assessment of neuromuscular changes from hydration status have done so with isokinetic and isometric muscle actions, thus making it more difficult to translate to the dynamic task seen during most anaerobic activities (Evetovich et al., 2002; Hayes \& Morse, 2010).

Electromyography (EMG) is commonly used to examine neuromuscular function during different hydration status and has shown that changes in neuromuscular function do not seem to be present (Bigard et al., 2001; Evetovich et al., 2002; Ftaiti et al., 2001; Hayes \& Morse, 2010; Judelson 
et al., 2007; Vallier et al., 2005). Evetovich et al, (Evetovich et al., 2002) showed no differences in EMG amplitude between hypo- and euhydrated conditions during both isometric and isokinetic contractions of the biceps brachii. Additionally, no changes were seen in torque during those same contractions. Similar results were seen by Hayes and Morse (Hayes \& Morse, 2010) during maximal voluntary contractions of the knee extensors (vastus lateralis) at progressively greater hypohydration in regards to EMG amplitude. However, a change in isometric strength and low velocity isokinetic strength $\left(30^{0} \mathrm{~s}^{-1}\right)$ were seen. Furthermore, no decrease in countermovement jump height was seen during the progressive hypohydration as this was used as a measure of lower-body power output (Hayes \& Morse, 2010). As high velocity isokinetic strength was maintained throughout the progressive dehydration, a subsequent increase in jump height should occur as a result of an increase in the strength to mass ratio, as hydration status was determined by reduction in body mass.

It has been shown that hydration status has little to no impact to the vertical jump height regardless if the countermovement or squat jump is used (S.N. Cheuvront, Carter, Haynes, \& Sawka, 2006; Samuel N. Cheuvront et al., 2010; Gutiérrez, Mesa, Ruiz, Chirosa, \& Castillo, 2003; Hayes \& Morse, 2010; Hoffman et al., 1995). However, it has been shown that jump height may not be the variable that best indicates a potential decrement in jumping performance as reductions in peak velocity and impulse have been seen when body mass is held constant (Samuel N. Cheuvront et al., 2010). This is interesting as some have suggested that jump height alone may not be indicative of presenting neuromuscular fatigue though the vertical jumping task is widely used as an assessment tool of neuromuscular fatigue in athletic populations (A. J. Coutts, Reaburn, Piva, \& Rowsell, 2007; A. Coutts, Reaburn, Piva, \& Murphy, 2007; Taylor, Chapman, Cronin, Newton, \& Gill, 2012). This has resulted in the use of variables calculated from jump height such as the reactive strength index modified which takes into account the time needed to reach a given jump height, thus creating a ratio of jump height over time to takeoff (Ebben \& Petushek, 2010). Moreover, it has been shown that ratings of perceived exertion and mood ratings have been impacted by hydration conditions both in aerobic and anaerobic based activity (Davis et al., 2015; Jones, Cleary, Lopez, Zuri, \& Lopez, 2008; Montain \& Coyle, 1992).

Athletes are classified as being in a hypohydrated state commonly before the onset of training sessions and competition (Osterberg, Horswill, \& Baker, 2009; Volpe, Poule, \& Bland, 2009). It is important then to understand how assessments commonly used such as the CMJ and SJ can be impacted by other factors that athletes face such as hypohydration, while also looking at the proposed mechanism to a reduction in performance concurrently. Thus, the purpose of this study was to assess the impact of hydration status on mean muscle activity during the propulsive phase of both the CMJ and SJ. Secondly, this study sought to find if ratings of perceived exertion and mood ratings were impacted by hydration state during the vertical jumping task.

\section{METHODS}

\section{Participants and Design}

Twenty recreationally trained males (height $181.03 \pm$ $8.61 \mathrm{~cm}$, body mass $85.24 \pm 12.13 \mathrm{~kg}$ ) between the age of 18 and 35 (age $23.95 \pm 2.67$ years) participated in this investigation. All subjects had participated in regular resistance training (3x per week) for the previous 6 months preceding data collection and where deemed to be free of injury and cleared for physical activity by the physical activity readiness questionnaire (PAR-Q). Informed consent approved from the University Institutional Review Board was obtained. A counterbalanced crossover design was used to assess the effect of hydration status on the muscle activation of both the countermovement and squat jump. Participants visited the laboratory for a total of four times, one familiarization session followed by three experimental sessions. Sample size estimation was conducted based on previous investigations using a repeated measures design similar to the present investigation (Samuel N. Cheuvront et al., 2010). The use a conventional $\alpha=0.05$ and $\beta=0.20$ and moderate effect size of 0.5 were used in the calculation.

\section{Testing Procedures}

When first arriving to all experimental sessions subjects were provided a sterile urine specimen cup to provide a midstream urine sample of less than 100 milliliters $(\mathrm{mL})$. Once the urine sample was collected, urine specific gravity (USG) was assessed using a digital pen refractometer (Atago USA Inc, Bellevue, WA) to ensure that the participants fell within the value range to be classified as being hypohydrated, (USG $\geq 1.022$ ) or euhydrated (USG $<1.015$ ) for that given session. To achieve the hypohydration, subjects were restricted to $500 \mathrm{~mL}$ of water in the 12 hours prior to arrival to the visit. All visits were conducted prior to 1000 am, thus the majority of the time spent in a fluid restriction was during periods of sleep. Euhydration was achieved by consuming water at a rate greater than normal daily consumption. No instructions were given as to water consumption for the control visit. In the event that the hydration status for either experimental session was not achieved participants were asked to return to the laboratory in two hours to reassess hydration status and determine if testing can be conducted on that day. Once classification had been deemed acceptable subjects were prepped for maximal voluntary contractions (MVC). The skin over the muscle belly of the vastus lateralis (VL), vastus medialis (VM), semitendinosus (ST) and medial gastrocnemius (MG) in the dominant leg was abraded and cleaned prior to the application of bipolar silver/silver chloride surface electrodes in accordance to recommendations of the SENIAM project (Hermens et al., 1999). A ground electrode placed on the tibial tuberosity. Leg dominance was determined by asking participants which leg they would kick a ball with if rolled to them. Standardized warm up was then performed, consisting of jumping jacks, body weight squats, quad and hamstring stretches and 5 submaximal CMJ and SJ attempts.

After completion of the warm up a 5-minute rest period was given prior MVC were collected. EMG signal was 
collected at $1000 \mathrm{~Hz}($ gain $=1000)$, using Noraxon Telemyo DTS 900 system (Scottsdale, AZ) through Vicon Nexus (Oxford, UK) software. Three trials of MVCs for each of the four muscles of interest were collected. MVCs were taken during knee extension, knee flexion and plantarflexion movements. Knee extension and flexion were performed on a padded weight bench with a leg extension attachment. Knee joint angle was set to ninety degrees. Subjects were asked to extend the leg as hard as possible into the leg extension attachment for five seconds followed by thirty seconds of rest for a total of three repetitions. Likewise, participants were asked to flex the leg into the pad as hard as possible for five seconds followed by thirty seconds of rest for a total of three repetitions. Plantarflexion MVCs were obtained by asking the subjects to press their toes into the ground as hard as possible while in the standing as hard as they can for five seconds with thirty seconds of rest between three trials (Allen, $\mathrm{Fu}$, \& Garner, 2016; Wilson et al., 2018).

Both CMJ and SJ were performed using a wooden dowel $(1.0 \mathrm{~kg})$ placed across the shoulders in a high bar squat position. Subjects completed one set of three jumps at a self-selected foot position and to a self-selected depth. Prior to each jump subjects were instructed to jump as explosively as possible to achieve maximal height. Preceding each jump, subjects were instructed to remain as still as possible to allow for body mass to be determined and then used in the calculation of the phases of jump as suggested by Chavda et al. (Chavda et al., 2018). The use of a 3, 2, 1, jump countdown was used for each trial. A period of three minutes of rest was given between sets of jumps.

Ratings of perceived exertion (RPE) using the $0-10$ OMNI-RES scale were taken at the end of each set of three jumps (Davis et al., 2015; Laurent et al., 2011). Furthermore, the use a 13 centimeter visual analog scale (VAS) was also used to assess mood ratings with the labels of "No motivation at all" on the far left side and "Highest possible amount of motivation" on the far right side of the line. Subjects then marked the location on the line corresponding to the level of motivation perceived at that time. The line was measured from the left to the nearest $0.01 \mathrm{~cm}$ (Jones et al., 2008).

\section{Data Analysis}

Ground reaction force data was collected using a 600 x 400$\mathrm{mm}$ force platform (Bertec Corp, Columbus, OH, USA). Force data was collected at $1000 \mathrm{~Hz}$. Jump height from the force platform was calculated using the impulse - momentum method. The propulsive phase of each CMJ trial was identified using methods described by Chavda et al., (Chavda et al., 2018) and McMahon et al., (McMahon, Suchomel, Lake, \& Comfort, 2018). Similar processing was adapted to SJ trials with the exclusion of an unweighting and braking phase. SJ analysis began by finding the mean of one second of weighting once at the self-selected depth and then identifying the first instance in which ground reaction forces exceeded 5 standard deviations above the mean of the one second weighting to signify the initiation of movement. From this point, methods were identical to those used in the analysis of the CMJ (Chavda et al., 2018). Only the propulsive phase of the $\mathrm{CMJ}$ and $\mathrm{SJ}$ were used to determine mean muscle activity and the percentage of MVC during the jumping task. Additionally, reactive strength index modified was calculated as the ratio of jump height as determined from force platform calculations over the time to take off calculated as the time from movement initiation to the point of takeoff

Raw EMG data was $4^{\text {th }}$ order Butterworth band-pass filtered $(20-250 \mathrm{~Hz})$ and full wave rectification was performed. Mean MVC was defined by observing mean amplitude second by second over the five second trial and choosing the greatest one second of mean amplitude. The mean of the three MVC trials were then used in the analysis and for further calculations. Mean muscle activity during each jump trial was calculated as the mean amplitude across the entire propulsive phase of the each jump trial. The mean of the three trials for each jumping technique was then used in the analysis. During each jump trial, the mean muscle activity was normalized as a percentage against the amplitude $(100 \%)$ corresponding to the 1 -s window of the peak MVC. Means values of the percentage of MVC across the three trials of the CMJ and SJ were then used in the analysis.

\section{Statistical Analysis}

A within-subject repeated measures analysis of variance was used to assess the effect hydration on MVC, mean EMG amplitude during the propulsive phase and percentage of MVC, RPE and VAS ratings. Mauchly's Test of sphericity was used test the assumption of sphericity for each variable. If the assumption was violated a Greenhouse - Geisser correction was used. Least significant difference post hoc analysis was used to determine where differences existed. All statistics were run in SPSS version 25 (IBM, Chicago, IL). An a priori alpha level of 0.05 was used in all analysis. Effect sizes are presented as Cohen's $d$ and interpreted using the criteria of trivial $(0.0-0.2)$, small $(0.2-0.6)$, moderate (0.6-1.2), large $(1.2-2.0)$, very large (2.0) and nearly perfect (4.0 or greater) as suggested by Hopkins (Hopkins, 2002). Effect sizes were first calculated as eta-squared values then converted to Cohen's $d$ to make for comparisons to other investigations (Cohen, 1988).

\section{RESULTS}

All results are reported as mean \pm SD. Significant differences between USG measures were present $\left(F_{2,38}=126.088\right.$, $p<0.001, d=5.15)$ with significant differences seen between all conditions (Table 1). No differences were seen in body mass across conditions $(84.2 \mathrm{~kg} \pm 12.7$ control, $84.6 \mathrm{~kg} \pm 12.6$ hypohydrated, and $85.6 \mathrm{~kg} \pm 12.6$ euhydrated). No differences were seen in any of the four muscles for MVC, mean muscle activity, and percentage of MVC (Table 1). No differences were seen between RSIm in either the CMJ or SJ (Table 1).

Significant differences were seen in the VAS $\left(F_{238}=3.31\right.$, $p=0.048, d=0.86$ ) (Figure 1). Post hoc test revealed differences between hypohydrated and euhydrated conditions $(\mathrm{p}=0.039)$. Differences were present between conditions in RPE after the SJ $\left(F_{2,38}=4.39, p=0.02, d=0.98\right)$ (Figure 2). Hypohydration $(3.26 \pm 2.32 \mathrm{SJ})$ was significantly higher 
Table 1. RSIm, Muscle Activity, and USG variables across conditions, Mean $\pm \mathrm{SD}$

\begin{tabular}{|c|c|c|c|c|c|c|}
\hline & \multicolumn{3}{|c|}{ СМJ } & \multicolumn{3}{|c|}{ SJ } \\
\hline & Control & Нуро & Eu & Control & Нуро & Eu \\
\hline RSIm & $0.75 \pm 0.23$ & $0.72 \pm 0.21$ & $0.73 \pm 0.18$ & $0.79 \pm 0.32$ & $0.74 \pm 0.28$ & $0.80 \pm 0.24$ \\
\hline \multicolumn{7}{|c|}{ Mean Muscle Activity (mV) } \\
\hline VL & $1.253 \pm 0.40$ & $1.086 \pm 0.37$ & $1.139 \pm 0.40$ & $1.173 \pm 0.38$ & $1.077 \pm 0.46$ & $1.067 \pm 0.27$ \\
\hline VM & $1.090 \pm 0.44$ & $1.090 \pm 0.42$ & $1.187 \pm 0.39$ & $1.074 \pm 0.54$ & $1.055 \pm 0.37$ & $1.082 \pm 0.36$ \\
\hline $\mathrm{ST}$ & $0.270 \pm 0.11$ & $0.261 \pm 0.09$ & $0.278 \pm 0.10$ & $0.232 \pm 0.10$ & $0.235 \pm 0.09$ & $0.257 \pm 0.10$ \\
\hline MG & $0.768 \pm 0.36$ & $0.755 \pm 0.75$ & $0.752 \pm 0.20$ & $0.67 \pm 0.37$ & $0.697 \pm 0.39$ & $0.636 \pm 0.14$ \\
\hline \multicolumn{7}{|c|}{$\% \mathrm{MVC}$} \\
\hline VL & $238.8 \pm 122.4$ & $234.9 \pm 130.7$ & $213.9 \pm 116.1$ & $179.3 \pm 121.4$ & $210.6 \pm 134.6$ & $183.4 \pm 73.1$ \\
\hline VM & $218.2 \pm 105.1$ & $246.1 \pm 81.6$ & $206.1 \pm 82.6$ & $172.8 \pm 131.3$ & $208.2 \pm 132.0$ & $170.7 \pm 63.3$ \\
\hline $\mathrm{ST}$ & $39.8 \pm 19.3$ & $38.7 \pm 23.7$ & $36.9 \pm 22.3$ & $26.3 \pm 13.8$ & $30.3 \pm 14.6$ & $29.4 \pm 15.1$ \\
\hline MG & $113.2 \pm 43.0$ & $123.2 \pm 31.8$ & $124.4 \pm 67.5$ & $78.9 \pm 48.3$ & $100.4 \pm 31.2$ & $98.7 \pm 55.7$ \\
\hline \multicolumn{7}{|c|}{ MVC (mV) } \\
\hline VL & $0.656 \pm 0.37$ & $0.656 \pm 0.38$ & $0.591 \pm 0.23$ & & & \\
\hline VM & $0.612 \pm 0.42$ & $0.541 \pm 0.27$ & $0.619 \pm 0.19$ & & & \\
\hline ST & $0.790 \pm 0.36$ & $0.805 \pm 0.42$ & $0.915 \pm 0.41$ & & & \\
\hline MG & $0.715 \pm 0.29$ & $0.638 \pm 0.25$ & $0.681 \pm 0.25$ & & & \\
\hline USG & $1.018 \pm 0.004^{*}$ & $1.023 \pm 0.002 *$ & $1.007 \pm 0.004 *$ & & & \\
\hline
\end{tabular}

RSIm: Reactive Strength Index Modified; MVC; Maximal Voluntary Contraction; VL: Vastus lateralis; VM: Vastus medialis; ST: Semitendinosus; MG: Medial Gastrocnemius: USG: Urine Specific Gravity $*=\mathrm{p}<0.001$

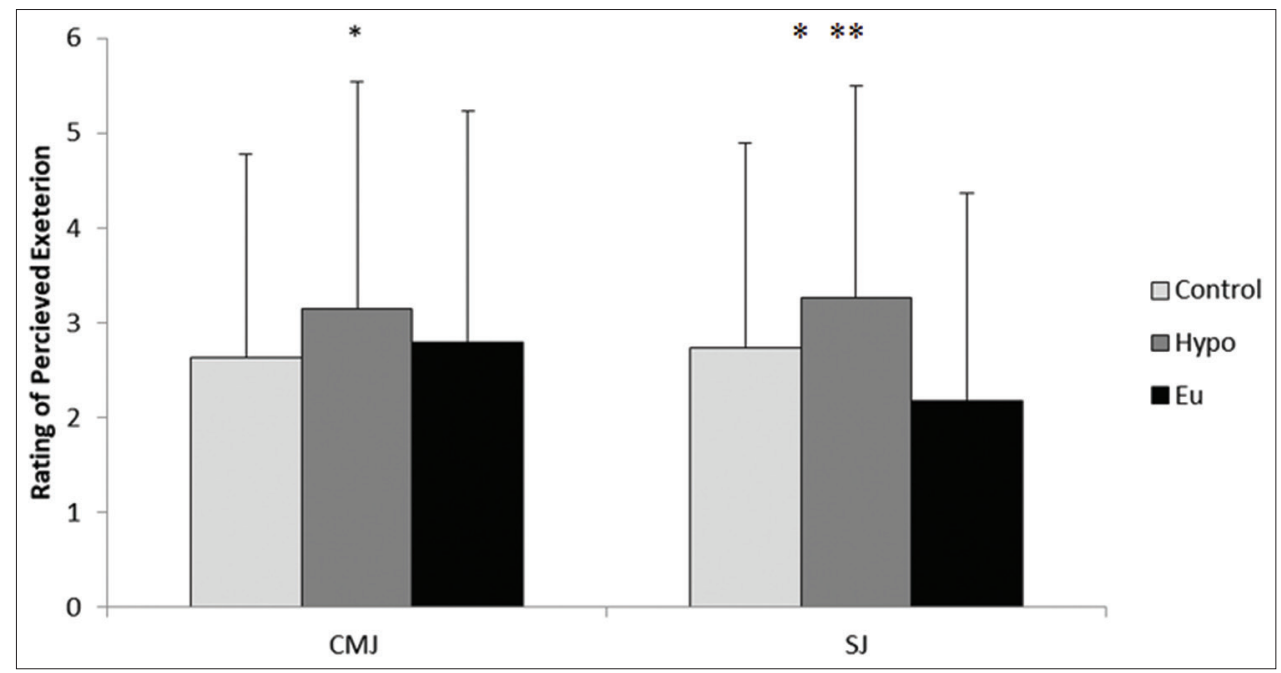

Figure 1. Comparison of RPE after each set of jumps across hydration conditions

* Significantly different from euhydrated at $\mathrm{p}<0.05$ level

** Significantly different from control at $\mathrm{p}<0.01$ level

than both the control $(2.73 \pm 2.15)$ and euhydrated $(2.18 \pm$ 2.15 ) conditions ( $p=0.004$ and 0.047 , respectively). Similar findings were present in RPE after the CMJ $\left(F_{2,38}=4.527\right.$, $p=0.02, d=1.00)$, with differences between the hypohydrated $(3.15 \pm 2.39)$ and control $(2.62 \pm 2.14)$ conditions $(\mathrm{p}=0.008)$ (Figure 2).

\section{DISCUSSION}

The primary findings of this investigation showed there was no difference in mean muscle activity between hydration status during MVCs and during the propulsive phases of both the CMJ and SJ. Differences were seen however in both RPE and mood ratings across conditions. To the authors knowledge this is the first study to investigate the impact of hydration status on mean muscle activity and percentage of MVC during the vertical jumping task. Previous investigations that examined hydration status on muscle activity were collected during isometric and isokinetic contractions (Evetovich et al., 2002; Hayes \& Morse, 2010). The present investigation sought to see if similar findings would be pres- 


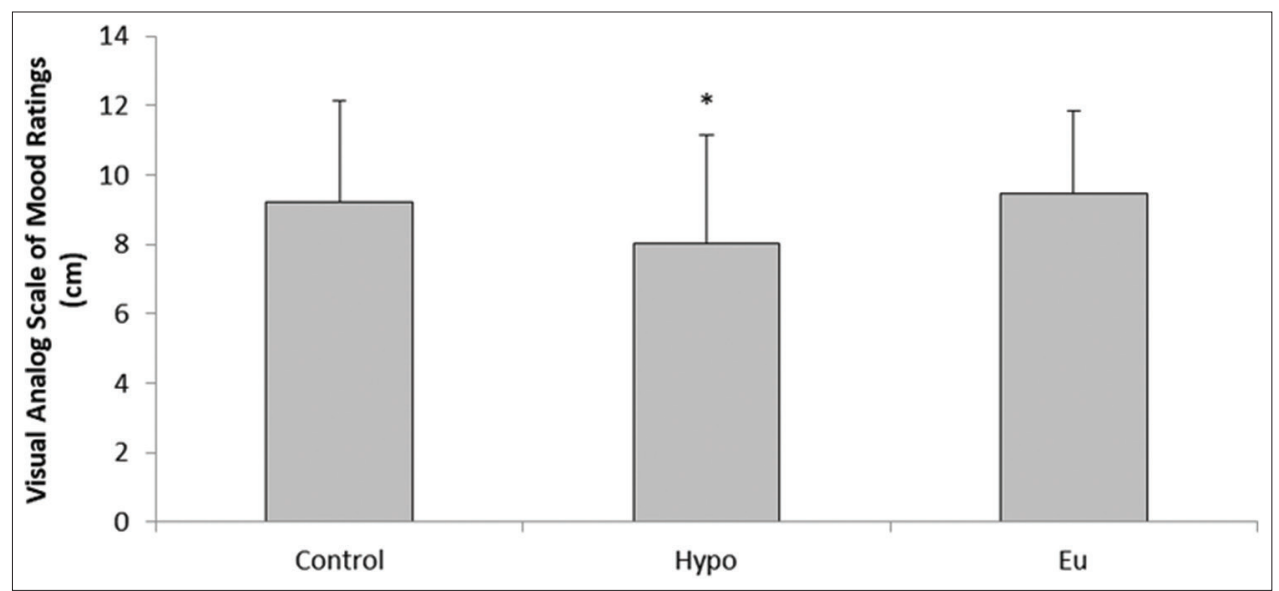

Figure 2. Mood Ratings across hydration conditions

* Significantly different from euhydrated at $\mathrm{p}<0.05$

ent during an explosive movement such as the vertical jump. Though not commonly seen, it is proposed that a decrement of anaerobic performance seen in hypohydrated conditions is caused by a change in the neuromuscular system.

In the present investigation it can be seen that the dehydration protocol was successful as there were significant differences between all conditions (Table 1). The protocol used to induce hypohydration during this investigation sought to limit confounding factors from heat and exercise exposure. Cutoff values for hypo- and euhydration were different than the traditionally USG value of 1.020 (Casa et al., 2000). This was used to ensure that there would be differences between conditions. Though differences were seen in hydration status there were no differences seen in RSIm (Table 1). This is similar to previous investigations that examined hydration and the vertical jumping task (Samuel N. Cheuvront et al., 2010; Gutiérrez et al., 2003; Hayes \& Morse, 2010; Hoffman et al., 1995). This would be expected as jump height is used in the calculation of RSIm and other investigations have shown no difference in jump height due to hypohydration. The advantage to using RSIm to jump height alone is that the factor of time, being that if it took longer to achieve a given jump height this would reduce the RSIm value. From the present data it seems that the CMJ height was not impacted by hydration status. However, there was a small to moderate effect size $(d=0.59)$ present in RSIm for the SJ. Similar results have been seen in SJ performance were a non-significant $4.7 \%$ reduction in jump height after heat induced hypohydration (Gutiérrez et al., 2003). Both the present investigation and that of Gutierrez et al. (Gutiérrez et al., 2003) showed that the CMJ was not impacted by hydration status while the SJ had a non-significant reduction. Thus, the countermovement itself during the CMJ may provide a mechanism to the attenuate the effects of hypohydration during the jumping task. Many previous investigations that have used the $\mathrm{CMJ}$ and jump height for the assessment of anaerobic power, could have found non-significant results that are a function of this attenuation mechanism of the countermovement.

EMG amplitude during MVC showed no differences between conditions. The present study supports the limited data between EMG amplitude during MVCs and hydration status (Evetovich et al., 2002; Hayes \& Morse, 2010). Furthermore, the present study shows that mean muscle activity during the propulsive phase of the vertical jump is not impacted by hydration status. When mean muscle activity was normalized against MVC, no differences were seen between conditions. A small to moderate effect was seen however in the VL $(d=0.43)$ and VM $(d=0.53)$ in the SJ. VL and VM percent of MVC was 27 and 38 percent higher respectively in the hypohydrated condition over the euhydrated. Similarly, VL and VM percent of MVC was 31.3 and 35.4 percent higher in the hypohydrated over the control. These results show that in the hypohydrated condition the knee extensor musculature had work at a greater rate to produce the same outcome as measured by RSIm. Similar findings were seen in the CMJ with a small to moderate effect in the VL $(d=0.33)$ and $\mathrm{VM}(d=0.41)$ with euhydration having the lowest value. It should be noted that during MVCs VM, ST, and MG all showed small to moderate effects $(d=0.46,0.41$, 0.37 respectively) of greater mean amplitude in the euhydrated condition. Thus, with near equal mean muscle activity during the SJ in all conditions, a greater percentage would be seen. The slightly higher MVC amplitude in the euhydrated condition agrees with Vallier et al. (Vallier et al., 2005) that showed no significant differences between conditions of hydration, but lower muscle activity during MVC in the fluid restricted condition in the VL. Contradicting findings were found by Evetovich et al. (Evetovich et al., 2002) were near identical amplitude was seem in isometric conditions and greater amplitude during isokinetic conditions in the biceps brachii.

RPE was taken to assess the impact that hydration status had in completing both the CMJ and SJ. Significant differences were seen in CMJ with higher values seen in the hypohydrated condition over the control condition and trending towards significance in with regard to the euhydrated. A similar pattern was seen in the SJ as hypohydration RPE was significantly greater than both the other conditions. These findings support those of Vallier et al. (Vallier et al., 2005) that used RPE values during prolonged cycling with fluid restriction, that over time higher RPE were seen to accomplish 
the same outcome of cycling at $\sim 60 \% \mathrm{VO}_{2}$ max for 3 hours. As endurance exercise has other factors related to hydration such as increase in heart rate and core temperature that are not seen in anaerobic exercise agreement between studies may be limited. Davis et al. (Davis et al., 2015) included RPE measures when examining intermittent sprinting and hydration state and found that when subject were hypohydrated, they expressed greater RPE values over euhydration after each bout of sprints. Additionally, Gann et al (Gann et al., 2016) showed that across multiple bouts of repeated sprints the dehydrated condition showed higher RPE measures than hydrated conditions. This trend was seen across multiple trials within the same bout. The results of the present investigation support the findings of previous investigations while adding an element that the jumping task that was performed is more anaerobic in nature then either of the previous investigations using RPE measures. VAS measures of mood ratings showed significant differences between hypohydration and euhydration. These findings support the findings of Jones et al (Jones et al., 2008) that used a similar scale during upper and lower body Wingate anaerobic testing. While significant differences were not seen between conditions, a 23 percent decrease was seen (Jones et al., 2008). Lower muscle activity during the MVC could be explained by these findings, that subjects were less motivated during the hypohydration. The results of higher RPE scores in both jumps and the decreased mood rating during hypohydrated sessions support the findings of greater percentage of MVC. The results of this study show that while completing both the SJ and CMJ to a similar outcome it was perceived as more difficult task as well as shown to take a greater muscle activity.

It should also be noted that differences were not seen between RPE and VAS measures in the control and euhydrated conditions. Though the euhydrated and control conditions were shown to represent different levels of hydration ( $p<0.001$ ), both would be classified as euhydrated using the traditional criterion value of USG $<1.020$ as a euhydrated (Casa et al., 2000). This shows that a potential dose response does not exist in regard to RPE and VAS measures. Similar findings were shown in faster isokinetic contraction velocities which would have been more similar to the contraction velocities seen in the present study (Hayes \& Morse, 2010). This is the first investigation to the author's knowledge that examined RPE and mood rating concurrently with anaerobic performance as it relates to hydration status. Thus, future investigations evaluate should include RPE or mood ratings along with task performance when examining the impact of hydration status. Limitations of this investigation include that torque or force measures were not taken concurrently during MVC. This could help in providing further insight as to how hydration status could impact isometric force production, though previous investigations show that force remains unaffected during isometric contractions. Additionally, the subjects used were recreationally trained males and results may differ for different levels of athletes as they may be more accustom to the $\mathrm{CMJ}$ and $\mathrm{SJ}$ from training and sport participation. However, the results from this investigation are similar to those in athletic populations with regard to RSIm (Ebben \& Petushek, 2010).
This investigation demonstrated that while the outcome of two of the more popular methods used in the assessment of athletes may not be impacted by hydration state, that the manner in which that outcome was achieved potentially could be influenced by the hydration state. As well it should be noted that when conducting assessments into the readiness of athletes that the inclusion of a simple hydration measure may provide practitioners and sport scientist additional information about the results of their assessments and the current state of the athlete.

\section{CONCLUSION}

This study found supporting evidence that no differences were seen in muscle activation during MVC as well as during the movement itself. However, a small to moderate effect was seen in the percentage of MVC that corresponds to higher RPE and lower mood ratings when hypohydrated. These findings are important to have a better understanding of how hydration impacts anaerobic performance measures such as the vertical jumping task, in addition to how hydration impacts tools used the assessment of athletes.

\section{REFERENCES}

Allen, C., Fu, Y.-C., \& Garner, J. C. (2016). The Effects of a Self-Adapted, Jaw Repositioning Mouthpiece and Jaw Clenching on Muscle Activity during Vertical Jump and Isometric Clean Pull Performance. International Journal of Kinesiology and Sports Science, 4(3), 42-49. https://doi.org/10.7575/aiac.ijkss.v.4n.3p.42

Bigard, A. X., Sanchez, H., Claveyrolas, G., Martin, S., Thimonier, B., \& Arnaud, M. J. (2001). Effects of dehydration and rehydration on EMG changes during fatiguing contractions. Medicine and Science in Sports and Exercise, 33(10), 1694-1700. https://doi. org/10.1097/00005768-200110000-00013

Casa, D. J., Armstrong, L. E., Hillman, S. K., Montain, S. J., Reiff, R. V., Rich, B. S. E.,... Stone, J. A. (2000). National Athletic Trainers' Association Position Statement: Fluid Replacement for Athletes. Journal of Athletic Training, 35(2), 212-224. https://doi.org/10.4085/10626050-50.9.07

Chavda, S., Bromley, T., Jarvis, P., Williams, S., Bishop, C., Turner, A. N.,... Mundy, P. D. (2018). Forcetime Characteristics of the Countermovement Jump: Analyzing the Curve in Excel. Strength and Conditioning Journal, 20(2), 67-77. https://doi.org/10.1519/ SSC. 0000000000000353

Cheuvront, S.N., Carter, R., Haynes, E., \& Sawka, M. (2006). No Effect of Moderate Hypohydration or Hyperthermia on Anaerobic Exercise Performance. Medicine \& Science in Sports \& Exercise, 38(6), 1093-1097. https://doi.org/10.1249/01.mss.0000222838.74015.15

Cheuvront, Samuel N., Kenefick, R. W., Ely, B. R., Harman, E. A., Castellani, J. W., Frykman, P. N.,... Sawka, M. N. (2010). Hypohydration reduces vertical ground reaction impulse but not jump height. European Journal of Applied Physiology, 109(6), 1163-1170. https://doi.org/10.1007/s00421-010-1458-y 
Cohen, J. (1988). Statistical power for the social sciences. In Hillsdale, NJ: Laurence Erlbaum and Associates.

Coutts, A. J., Reaburn, P., Piva, T. J., \& Rowsell, G. J. (2007). Monitoring for overreaching in rugby league players. European Journal of Applied Physiology, 99(3), 313-324. https://doi.org/10.1007/s00421-006-0345-z

Coutts, A., Reaburn, P., Piva, T. J., \& Murphy, A. (2007). Changes in selected biochemical, muscular strength, power, and endurance measures during deliberate overreaching and tapering in rugby league players. International Journal of Sports Medicine, 28(2), 116-124. https://doi.org/10.1055/s-2006-924145

Davis, J. K., Laurent, C. M., Allen, K. E., Green, J. M., Stolworthy, N. I., Welch, T. R., \& Nevett, M. E. (2015). Influence of dehydration on intermittent sprint performance. Journal of Strength and Conditioning Research, 29(9), 2586-2593. https://doi.org/10.1519/ JSC.0000000000000907

Ebben, W. P., \& Petushek, E. J. (2010). Using the reactive strength index modified to evaluate plyometric performance. Journal of Strength and Conditioning Research, 24(8), 1983-1987. https://doi.org/10.1519/ JSC.0b013e3181e 72466

Evetovich, T. K., Boyd, J. C., Drake, S. M., Eschbach, L. C., Magal, M., Soukup, J. T.,... Weir, J. P. (2002). Effect of moderate dehydration on torque, electromyography, and mechanomyography. Muscle and Nerve, 26(2), 225-231. https://doi.org/10.1002/mus.10203

Fogelholm, M. (1994). Effects of Bodyweight Reduction on Sports Performance. Sports Medicine, Vol. 18, pp. 249-267. https://doi.org/10.2165/00007256-19941804000004

Ftaiti, F., Grélot, L., Coudreuse, J. M., \& Nicol, C. (2001). Combined effect of heat stress, dehydration and exercise on neuromuscular function in humans. European Journal of Applied Physiology, 84(1-2), 87-94. https://doi org/10.1007/s004210000339

Gann, J. J., Green, J. M., O’Neal, E. K., Renfroe, L. G., Andre, T. L., McBride, C., \& Neal, K. (2016). Effects of Hypohydration on Repeated 40 Yard Sprint Performance. Journal of Strength and Conditioning Research, 30(4), 901-909. https://doi.org/10.1519/ JSC.0000000000001177

Gutiérrez, A., Mesa, J. L. M., Ruiz, J. R., Chirosa, L. J., \& Castillo, M. J. (2003). Sauna-induced rapid weight loss decreases explosive power in women but not in men. International Journal of Sports Medicine, 24(7), 518-522. https://doi.org/10.1055/s-2003-42017

Hayes, L. D., \& Morse, C. I. (2010). The effects of progressive dehydration on strength and power: Is there a dose response? European Journal of Applied Physiology, 108(4), 701-707. https://doi.org/10.1007/s00421-0091288-y

Hermens, H., Freriks, B., Merletti, R., Hägg, G., Stegeman, D., Blok, J.,... Disselhorst-Klug, C. (1999). European Recommendations for Surface ElectroMyoGraphy, results of the SENIAM project. Roessingh Research and Development b.V.
Hoffman, J. R., Stavsky, H., \& Falk, B. (1995). The effect of water restriction on anaerobic power and vertical jumping height in basketball players. International Journal of Sports Medicine, 16(4), 214-218. https://doi. org/10.1055/s-2007-972994

Hopkins, W. G. (2002). A scale of magnitudes for effect statistics. Retrieved January 8, 2019, from Sportscience website: http://www.sportsci.org/resource/stats/effectmag.html

Jones, L. C., Cleary, M. A., Lopez, R. M., Zuri, R. E., \& Lopez, R. (2008). Active dehydration impairs upper and lower body anaerobic muscular power. Journal of Strength and Conditioning Research, 22(2), 455-463. https://doi.org/10.1519/JSC.0b013e3181635ba5

Judelson, D. a, Maresh, C. M., Anderson, J. M., Armstrong, L. E., Casa, D. J., Kraemer, W. J., \& Volek, J. S. (2007). Hydration and muscular performance: does fluid balance affect strength, power and high-intensity endurance? Sports Medicine, 37(10), 907-921. https://doi.org/10.2165/00007256200737100-00006

Laurent, C. M., Green, J. M., Bishop, P. A., Sjökvist, J., Schumacker, R. E., Richardson, M. T., \& Curtner-Smith, M. (2011). A practical approach to monitoring recovery: Development of a perceived recovery status scale. Journal of Strength and Conditioning Research, 25(3), 620-628. https://doi.org/10.1519/ JSC.0b013e3181c69ec6

McMahon, J. J., Suchomel, T. J., Lake, J. P., \& Comfort, P. (2018). Understanding the Key Phases of the Countermovement Jump Force-Time Curve. Strength and Conditioning Journal, 40(4), 96-106. https://doi.org/10.1519/ SSC.0000000000000375

Montain, S. J., \& Coyle, E. F. (1992). Influence of graded dehydration on hyperthermia and cardiovascular drift during exercise. Journal of Applied Physiology, 73(4), 1340-1350. https://doi.org/10.1152/jappl.1992.73.4.1340

Osterberg, K. L., Horswill, C. A., \& Baker, L. B. (2009). Pregame urine specific gravity and fluid intake by national basketball association players during competition. Journal of Athletic Training, 44(1), 53-57. https://doi. org/10.4085/1062-6050-44.1.53

Taylor, K.-L., Chapman, D. W., Cronin, J. B., Newton, M. J., \& Gill, N. (2012). Fatigue Monitoring in High Performance Sport: a Survey of Current Trends. Journal of Australian Strength and Conditioning, 20(1), $12-23$.

Vallier, J.-M., Grego, F., Basset, F., Lepers, R., Bernard, T., \& Brisswalter, J. (2005). Effect of fluid ingestion on neuromuscular function during prolonged cycling exercise. British Journal of Sports Medicine, 39(4), 1-6. https://doi.org/10.1136/bjsm.2004.012393

Viitasalo, J. T., Kyröläinen, H., Bosco, C., \& Alen, M. (1987). Effects of rapid weight reduction on force production and vertical jumping height. International Journal of Sports Medicine, 8(4), 281-285. https://doi. org/10.1055/s-2008-1025670 
Volpe, S. L., Poule, K. A., \& Bland, E. G. (2009). Estimation of Prepractice Hydration Status of National Collegiate Athletic Association Division I Athletes. Journal of Athletic Training, 44(6), 624-629. https://doi. org/10.4085/1062-6050-44.6.624

Walsh, R. M., Noakes, T. D., Hawley, J. A., \& Dennis, S. C. (1994). Impaired high-intensity cycling performance time at low levels of dehydration. International Journal of Sports Medicine, 15(7), 392-398. https://doi. org/10.1055/s-2007-1021076

Wilson, S. J., Williams, C. C., Gdovin, J. R., Eason, J. D., Luginsland, L. A., Hill, C. M.,... Garner, J. C. (2018). The Influence of an Acute Bout of Whole Body Vibration on Human Postural Control Responses. Journal of Motor Behavior, 50(5), 590-597. https://doi.org/10.108 0/00222895.2017.1383225 